\section{Follow up after transurethral resection of prostate: Who needs it?}

\author{
Thomas H Lynch, Brian Waymont, \\ Christopher J M Beacock, J A Dunn, \\ Michael A Hughes, D Michael A Wallace
}

Department of Urology, Queen Elizabeth Medical Centre, Birmingham B15 2TH

Thomas H Lynch, FRCS, research fellow

Brian Waymont, FRCS, research fellow Christopher J M Beacock, FRCS, senior registrar

J A Dunn, MSC, statistician Michael A Hughes, FRCS, consultant

D Michael A Wallace, FRCs, consultant

Correspondence to:

Mr Lynch.

$B M \mathcal{F}$ 1991;302:27 has not previously been examined.

\section{Patients, methods, and results}

About 31000 transurethral prostatectomies are performed in England annually.' We carried out a prospective study of 111 consecutive patients undergoing transurethral resection of the prostate for benign hyperplasia to determine the need for routine follow up after surgery. The value of a routine outpatient visit

The patients were admitted from the waiting list or as emergencies with acute retention. Before surgery they were given a standard leaflet explaining the procedure. On discharge they were given a second leaflet outlining the likely complications in the early postoperative period but were not offered routine outpatient review. A letter giving similar details was sent to their general practitioner. After three months a questionnaire asking for details of urinary symptoms and their management and about the desirability of routine follow up was sent to the patients and the general practitioners. The data were analysed with the biomedical data program. ${ }^{2}$

Twelve patients were unsuitable for analysis: two had unsuspected prostatic carcinoma; two requested routine outpatient review; one died of a condition not related to prostatectomy; and seven were excluded because they or their general practitioner returned incomplete questionnaires. We therefore studied 99 patients. Completed questionnaires were returned from $104(94 \%)$ patients and $106(96 \%)$ general practitioners.

The characteristics of the 35 patients who expressed a desire for follow up were compared with those of the remaining 64 patients (table). The only significant difference between the groups was that those in whom $<20 \mathrm{~g}$ tissue had been resected were more likely

Details of 99 patients who responded to questionnaire about desirability of routine follow up after transurethral prostatectomy

\begin{tabular}{|c|c|c|c|c|}
\hline & \multicolumn{2}{|c|}{ Outpatient follow up } & \multirow[b]{2}{*}{$\chi^{2}$} & \multirow[b]{2}{*}{ p Value } \\
\hline & $\begin{array}{l}\text { Preferred } \\
(\mathbf{n}=35)\end{array}$ & $\begin{array}{c}\text { Not preferred } \\
(n=64)\end{array}$ & & \\
\hline \multicolumn{5}{|l|}{ Age (years): } \\
\hline $\begin{array}{l}<70 \\
\geqslant 70\end{array}$ & 21 & 30 & 1.56 & $0 \cdot 21$ \\
\hline$\geqslant 70$ & 14 & 34 & & \\
\hline \multicolumn{5}{|c|}{ Type of admission: } \\
\hline Emergency & 5 & 17 & $1 \cdot 97$ & $0 \cdot 16$ \\
\hline Waiting list & 30 & 47 & & \\
\hline \multicolumn{5}{|c|}{ Catheter inserted preoperatively: } \\
\hline No & 29 & 45 & $2 \cdot 70$ & $0 \cdot 10$ \\
\hline Yes & 5 & 19 & & \\
\hline \multicolumn{5}{|c|}{ Urinary tract infection preoperatively: } \\
\hline No & 30 & 53 & $0 \cdot 50$ & $0 \cdot 48$ \\
\hline Yes & 4 & 11 & & \\
\hline \multicolumn{5}{|c|}{ Amount of tissue resected (g): } \\
\hline$<20$ & 22 & 28 & $3 \cdot 9$ & 0.05 \\
\hline$\geqslant 20$ & 12 & 36 & & \\
\hline \multicolumn{5}{|c|}{ Blood transfusion given: } \\
\hline Yes & 27 & 43 & $0 \cdot 87$ & $0 \cdot 35$ \\
\hline No & 8 & 20 & & \\
\hline \multicolumn{5}{|c|}{ Time for which catheter in place postoperatively (days): } \\
\hline$\leqslant 2$ & 23 & 42 & 0.001 & 0.99 \\
\hline$>2$ & 12 & 22 & & \\
\hline \multicolumn{5}{|c|}{ Urinary tract infection postoperatively: } \\
\hline No & 29 & 57 & 1.21 & $0 \cdot 27$ \\
\hline Yes & 6 & 6 & & \\
\hline \multicolumn{5}{|c|}{ Time in hospital (days): } \\
\hline$\leqslant 7$ & 23 & 42 & 0.01 & 0.92 \\
\hline$>7$ & 12 & 21 & & \\
\hline
\end{tabular}

to want follow up $(p=0 \cdot 05)$. Twenty five general practitioners expressed a desire for routine follow up, but on only 10 occasions was there concordance between a patient and his general practitioner. Fifty three patients consulted their general practitioner after discharge, and in 36 cases the general practitioner thought that a routine appointment at the clinic was not necessary. There were eight patients who did not consult their general practitioner but whose general practitioner thought that a routine outpatient visit was desirable. Seven patients required readmission and three were referred to the outpatient department.

No correlation was found between the prevalence of adverse perioperative factors, such as urinary tract infection before and after operation, chronic urinary retention, and bleeding requiring a blood transfusion of more than two units, and the number of consultations with the general practitioner, the incidence of postoperative urinary symptoms, and preference for follow up.

\section{Comment}

We found that we could not predict which patients were likely to have persisting symptoms, consult their general practitioner, or prefer a follow up consultation. Patients in whom a smaller amount of tissue had been resected were more likely to have persistent symptoms, and this supports the findings of other authors. ${ }^{34}$ The lack of concordance between general practitioners and patients about the desirability of follow up suggests that they may have different expectations.

The most potent arguments for continuing routine follow up are that it is useful for audit, training junior staff, and checking the histological diagnosis as this is often not available at discharge. In this unit a monthly computer check ensures that each discharge summary, including the histology report, has been forwarded to the general practitioner and any unsuspected malignancies are thus detected.

If follow up attendances are thought to be necessary their timing poses a dilemma. Our routine practice was to review patients six weeks after prostatectomy. The results of this study, however, suggest that this is too late to treat most postoperative problems and too early to assess the results of surgery. We found that patients in whom outcome was poor were quick to return whether referred by their general practitioner or not. We believe, therefore, that routine hospital follow up of patients after uncomplicated transurethral resection of the prostate serves little useful purpose and places an unacceptable burden on patients, staff, and resources.

We thank those general practitioners and patients who returned the questionnaires and Mr D Hahn and Dr A Raine, who collected some of the data.

1 Office of Population Census and Surveys. Hospital in-patient enquiry. London: HMSO, 1985. (Series MB4 No 27.

2 Anonymous. BMDP statistical software manual. Vol 1, 2. Los Angeles: BMDP Statistical Software Inc, 1988.

3 Singh M, Tressider GC, Blandy JP. The evaluation of transurethral resection for benign enlargement of the prostate. Br $\mathcal{A}$ Urol 1973;45:93.

4 Dorflinger T, England DM, Madsen CG, Bruskewitz RC. Urodynamic and histological correlates of benign hyperplasia. I Urol 1988;140:1487-90.

(Accepted 11 September 1990

\section{Correction}

Cost of surfactant replacement treatment for severe neonatal respiratory distress syndrome

An authors' error occurred in this paper by Dr T R J Tubman and colleagues (13 October, p 842). In the results section of the abstract the length of care should be 95 days per extra survivor in the treatment group and not 91 days as published. 